\title{
THE OCULAR MANIFESTATIONS OF HYSTERIA IN RELATION TO FLYING*
}

\author{
BY \\ Air-Commọdore REDVĖRS IRONSIDE, M.B.(Aber.), \\ F.R.C.P.(Lond.), R.A.F.V.R. \\ and
}

Flight Lieut. I. R. C. BATCHELOR, M.B.(Edin.), R.A.F.V.R.

IT may be stated at the outset that neurosis in any member of aircrew is relatively uncommon. This is largely due to careful administrative selection, rigorous medical standards, and the weeding-out process that takes place throughout flying training. Air Commodore Livingston has formulated the standards for visual fitness for aircrew duties ih the present war, and his standards have been accepted as the criteria of normality.

It is not surprising that a few potentially unstable individuals pass this filter, sometimes suppressing at their time of entry information which, if divulged, would have led to their rejection. It is chiefly this small group of misfits who subsequently break down under conditions of stress. The peculiar nature of flying duties throws particular strains upon the whole visual apparatus. Over a period of three years occupied in regular neuropsychiatric examination of aircrew we have collected a series of 40 cases of ocular manifestatións of hysteria. In ophthalmological textbooks little space is devoted to this subject. The common manifestations of hysterical blindness, hysterical contraction of the visual fields, and glare asthenopia aie well recognised. Traquair ${ }^{1}$ (1942) has fully described the field changes in neurasthenia and in hysteria and his work must be consulted for reference to bizarre visual field findings, including some forms of ring scotomata in hysteria. Hurst $^{2}(1940)$ has made reference to defective accommodationconvergence in neurotic soldiers. A recent paper by Michaelson ${ }^{3}$ (1943) describes manifestations found in soldiers in the Middle East. More recently the matter has be'n the subject of discussion at the Royal Society of Medicine ${ }^{4}$ (1944).

It is understandable that in pilots and other members of aircrews manifestations of hysteria should affect the eyes rather than the limbs, for what his legs are to an infantryman, his eyes are to a pilot. Aircrew duties involve searching the ground and sky by day and night, exerting a constant vigilance over dials and instruments of precision, the transference of attention from the instrument

a panel to the horizon, and making judgments in conditions of varying visibility. The eyes are subjected to glare from the sun

\footnotetext{
* Received for publication, December 8, 1944.
} 
and from the sea, and sudden blinding by searchlights or by lightining flash. These stresses on the visual apparatus are doubtless responsible for the rich variety of clinical pictures presented in aircrew. Nothing comparable to this is seen in civil practice with perhaps the exception of compensation cases following upon head injury, and in certain types of miners' nystagmus. The disorders which are described are not those of seeing, but of looking; they are disorders of higher cerebral functions. As Traquair says, "The interference is with the will of the patient, and such functions as perception, appreciation, attention and response are involved; in other words, it is the patient who is at fault, and not his visual mechanism."

\section{Visual aberrations experienced by normal aircrew}

Under conditions of fatigue, anoxia and anxious preoccupation certain visual aberrations may be noted in normal individuals.

Certain individuals engaged for-long hours in flying on instruments describe what they call "fatigue spells." They say that the instrument panel becomes blurred or may appear to oscillate for a few seconds whilst they become momentarily dazed. The condition is usually rectified by shifting the gaze and shaking the head or rubbing the eyes.

The effects of anoxia on vision, particularly night vision, are well known. At 16,000 feet the rate of adaptation decreases considerably, and there is an average percentage decrease in the range of night. vision of 40 per cent., if oxygen is not used. Under conditions of anoxia almost all subjective ocular symptoms may occur. Members of aircrew who delay turning on their oxygen supply at night and commence to use it above 10,000 feet may experience nausea, and either a sudden brightening or a rose-red clouding of the visual field. These visual sensations last two minutes at the most, until the oxygen debt has been paid off.

Visual after-sensations may be noted in conditions of anxious preoccupation. Thus when crossing a coastline after flying over the sea for long hours a vision of the waves may appear between the pilot and the land. This after-lag is like the main sensation, only weaker, and rarely persists for more thán a few seconds.

Diplopia may sometimes be experienced. When the eyes of a normal individual are directed upon a near point, more distant objects are seen double. When the eyes are directed to a distant point, nearer objects are seen double. (This can be demonstrated by holding a pencil a foot, in front of the eyes in line with a distant object.)

This paper however is not concerned with physiological phenomena found in normal individuals, and they are mentioned here only that they may be distinguished from grosser, more persistent and more disabling phenomena due to neurosis. 


\section{Cases of hysteria and of affective disorder compared .}

The majority of our cases of psychoneurosis have shown a mixed reaction type, but in most one reaction has predominated. This paper deals mainly with cases of hysteria, and in particular with a series of forty. Cases of hysteria and of affective disorder generally show differences in their ocular symptoms and signs. In our experience, about one-fifth of cases of hysteria, but only about one-tenth of cases of affective disorder, have complained of visual symptoms. In the cases of hysteria the visual complaints, when they existed, have almost always been the primary and disabling symptom : in the cases of affective disorder they have constituted one symptom of many, not in itself disabling. On the other hand, it certainly happens that cases whose initial hysterical symptoms have not been ocular, develop ocular symptoms and signs as the result of the suggestions implicit in close questioning and examination: and ocular symptoms occasionally are developed as a laşt resource of evasion, when no organic basis has been found for other symptoms and the individual faces the prospect of a return to duty. The symptomatology also of the two conditions is somewhat different. Of those with visual complaints, one-half of the cases of affective disorder complained of aching eyes, while only one-tenth of the cases of hysteria did : and blurring of vision, a disabling symptom usually, has been twice as common in cases of hysteria. These distinctions are of some diagnostic value.

\section{The ocular symptomatology of hysteria}

The symptoms presented by these cases are similar to those complained of by patients with organic ocular defects and diseases, , with few exceptions when the symptoms are unusual and may be expressed in bizarre terms. A list of the symptoms complained of in the 40 cases under review are presented in the table in order of frequency. Complaints of extra-ocular symptoms of which the commonest is headache have not been included. The 40 cases comprised 23 pilots, 10 gunners and 7 observers.

\section{Table of Symptoms.}

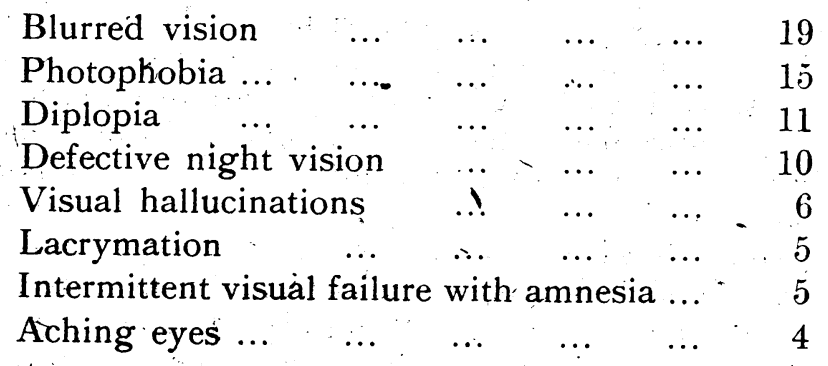


$\begin{array}{llllll}\text { Difficulty in judging distances } & \ldots & \ldots & 4 \\ \text { Blepharospasm } & \ldots & \ldots & \ldots & \ldots & 2 \\ \text { Looking past objects } & \ldots & \ldots & \ldots & 1 \\ \text { Intermittent loss of vision } & \text { in one eye } & \ldots & 1 \\ \text { Film over one eye } \ldots & \ldots & \ldots & \ldots & 1 \\ \text { Involuntary movement of one eye } & \ldots & 1 \\ \text { Jumbling of print } & \ldots & \ldots & \ldots & \ldots & 1 \\ \text { Failing day vision } & \ldots & \ldots & \ldots & \ldots & 1\end{array}$

Characteristically, the symptoms are disabling considered in the setting of the duties which the individual has to perform. Thus those engaged in night flying may complain of failing night vision; those who have to watch dials continuously, of intermittent visual failure. The symptoms as expressed may indícate that the individual's eyes have become so unreliable that when flying in formation or with a crew he could no longer be considered to be a reliable person. Intermittency of the disabling symptom is sometimes a feature.

The symptoms are out of proportion to any ocular disability which may be present. If a refractive error or phoria is found, it is always insufficient to account fully for the degree of discomfort or disability experienced by the individual, or for the number and variety of the symptoms which he presents. Thus an instructor who had flown 2,500 hours complained of photophobia, headaches, recent failure of vision by day and night, and constant lac rymation, and showed no significant ocular abnormality: $\mathrm{He}$ had one prism dioptre of exophoria, and was emmetropic.

The disability may be stated in terms of performance rather than of symptoms, the patient complaining that he is no longer able to judge distances when flying in formation or when coming in to land: Or an individual who has damagéd an aircraft in a faulty landing may attribute his poor performance to an ocular defect. In such cases the is an uncertain distinction from malingering. On the other hand, we have noted that the hysterical response- to stress is not infrequently delayed.

Not all of these patients were free from anxiety; most, however, were placid, or gave a superficial impression of quiet confidence.

In nearly every case reference was first made to an ophthalmologist, and when the visual findings were discovered to be within normal limits or when the disproportion between symptoms and signs was noticed, the case was then referred to a psychiatrist. No case was accepted as hysterical unless positive evidence of psychoneurosis could be demonstrated on psychiatric examination.

The following visual hallucinations were noted: approach (in focus) of objects in the upper parts of the visual fields; hairs of light around objects and wavy oscillations of the tops and bottoms 
of mountains; oscillation of the moon; seeing coastlines that did not exist, on a clear day; bubbles in front of the eyes; flashes of red light. Three cases of micropsia alse came under review, but are not included in this series: These were of considerable interest as micropsia is characteristic of organic, particularly toxic or confusional, states. In two pilots who had this symptom the complaint was that everything was seen a long way away, as if through the wrong end of a telescope. One of these patients had as many as 4-5 attacks of this a day, each attack lasting from 5-60 minutes. In one case it was associated with a feeling as if his tongue and body generally were becoming enlarged. The onset of the symptoms in both was during flying training, but in one case there had been a previous micropsia during a febrile illness in childhood. In another case, in an air gunner, the symptoms were noticed only in artificial light. All of these patients were of markedly neurotic constitution, but the presence of an organic basis for their symptom could not be confidently excluded, as they were not under prolonged observation.

A not inconsiderable group of cases of migraine syndrome with visual distūrbances in association with affective disorder, have been excluded from this survey.

Five cases complained of intermittent visual failure with transient amnesia. The opinion formed, after detailed investigation, was that the-amnesia was of hysterical and not of epileptic origin. Three of the cases of temporary blindness occurred on the ground, the attacks lasting as long as 45 minutes : during. this period the individual had to be led about by a companion.

\section{The objective findings on examination}

Any of the functional components of the eyes may be affected, and changes may. be seen in striped and unstriped muscle, glands and blood vessels. On examination, blinking, coarse tremor of the closed eyelids, and blepharospasm are common. Suffusion of the conjunctivae and lacrymation may be present. Inconsistencies and variabilities are commonly noted by the examiner in the course of routine testing or on repeated examination. On testing the conjugate movements of the eyes the movements of the examiner's finger are frequently anticipated, the ocular movements are poorly controlled and fixation is not maintained. Nystagmoid jerkings may be noted. All degrees of heterophoria are found ( 11 out of 40 cases). There may be variable frank squint, with or without diplopia. The psychological disorder may render. manifest a latent squint with associated diplopia. In cases of concomitant squint, the psychological disorder may cause an image previously suppressed to become obtrusive. Two of our cases showed an alternating neglect. More than a quarter 
showed a convergence weakness (i.e., convergence not achieved closer than $10 \mathrm{cms}$.), and convergence may at first be absent on examination and later achieved by persuasion. The individual may converge better on his own finger than on the examiner's. Most curious afe dissociations between convergence of the visual axes and contraction of the pupils : thus one may find convergence without pupillary contraction, or exceedingly rarely pupillary contraction without convergence. Variable convergence spasm may be present, the eyes tending to converge- at rest, or there may. be spasm of accommodation : a case of each occurred in this series. The most bizarre signs are demonstrated by " ocular gymnasts," who have the capacity for independent movement of the eyes : thus one subject could fix with his right eye and adduct his left strongly towards the midline.

The behaviour of the subject during examination is most notable. He is usually ill at ease. His replies are inconsistent and evasive. He has various mannerisms-the persistent wearing of dark glasses, the pained passing of his hand over his eyes and back over his head, tilting of his head, and rearing of his head when attempting convergence. The latter mày be associated with lid retraction. The ocular signs may be altered or abolished by suggestion and persuasion, but this, though highly characteristic, is not pathognomonic of hysterical visual disorder.

Ordinary tests of night vision are of little value in hysteria, as the-tests are subjective, and if the individual is unwilling to see he will not see. By the use of an adaptometer, however, in which the intensity of light may be varied quickly, it may be possible. to detect inconsistencies in the replies of hysterical subjects or malingerers. Those who complain of defective night vision will almost certainly, on testing, give results indicating low capacity. But provided that there is no ocular abnormality discoverable on examination, and the individual does not give a history suggestive of constitutional night blindness (which is a very rare condition), it may be confidently assumed that failing night vision is not due to organic disease.

The only case of hysterical contraction of the visual fields, perhaps the commonest hysterical ocular finding in civil practice, was noted in an individual who complained of failing vision before he ever started to learn to fly.

Minor refractive errors, phorias or minor degrees of blepharitis were present in some of the cases. It is possible, however, to state that in all cases the findings on physical examination came within the limits of the standards laid down by Air Ministry for fitness for aircrew duties. From the physical standpoint these men. were fit for the exacting visual requirements of aircrew. 


\section{Two illustrative case histories}

(1) Squadron-Leader A., D.F.C., Bomber Pilot. Towards the end of a completed tour of night sorties he began to suspect that he was suffering from eyestrain, and experienced blinding headaches. He consulted a civil ophthalmologist privately as he feared he might be taken off flying, and it is not known what he was told. He completed his tour and was decorated.

On subsequent non-operational flying he complained of photophobia and began to wear dark glasses. He was posted to a squadron for further operational flying but began to make high and erratic landings (after 1,000 hours' flying experience), and reported sick with transient attacks of double vision.

Examination on April 26, 1941, showed that his visual acuity in each eye tested separately was $6 / 6$; convergence was poorly sustained and the effort was stated to cause pain; his conjunctivae were suffused; the ocular findings were otherwise normal, but later in the examination his visual acuity with both eyes tested together was noted to be $6 / 24$. On June 9,1941 , his visual acuity was $6 / 18$ in "each eye and it. was noted "vision will not correct to $6 / 6$, no reason found." His diplopia recurred and it was then suspected that he had disseminated selerosis, but neurological examination showed no abnormality.; and the inconsistencies and incompatibilities of the ocular findings could not be explained on organic grounds. He was seen by Air Commodore Livingston, who referred him for psychiatric examination.

Comment: This case illustrates well the characteristic ocular findings in hysteria, and the influence of suggestion in producing variations and inconsistencies on repeated examinations. The latent period in the development of signs and their time relationship to stress of operational flying are important. It would have been easy but incorrect to ascribe this officer's symptoms to fatigue, but for six months before he came under observation his flying duties had not been arduous.

(2) Sergeant B., Fighter Pilot. After 100 operational hours in Malta he was invalided home with eye symptyoms, with a report from his O.C. which described him as very keen. He stated that he had felt perfectly fit apart from intolerance of light, lacrymation and bi-temporal pressure headaches. These symptoms did not interfere with his flying except when he had to fly above 20,000 feet and keep constant look-out in conditions of bright sunshine.

On examination he showed mild conjunctival injection, visual acuity was $6 / 5$ in each eye, objective convergence $=8 \mathrm{cms}$, accommodation $=14 \mathrm{cms}$. ; he had 0.5 prism dioptre of hyperphoria in the right eye and 1.5 prism dioptres of esophoria in the left. Five months later his visual acuity was $6 / 6$ in each eye, convergence $=7 \mathrm{cms}$., accommodation $=12 \mathrm{cms}$., and he showed 
one dioptre of manifest hypermetropia. Ocularly he was fit for full operational category but his symptoms remained. He was then referred for psychiatric examination.

It was found that he had had neurotic visual symptoms before entry which entailed his giving up studying for an examination. The recurrence of his symptoms dated from severe operational stress in Malta, of which he had previously made light.

Comment : It is to be observed that the neurotic nature of his complaint was not suspected on the squadron as he displayed no anxiety or lack of keenness to fly. The variation in the ocular findings and their ultimate disappearance with persistence of the symptoms is important. The symptoms as stated were subjectively a disability for his operational duties, which involved flying at 30,000 feet and keeping constant look-out for enemy aitcraft likely to attack out of the sun.

\section{The relationship of neurotic manifestations to inherent ocular defects}

We do not subscribe to the view that all heterophorias and defects of ocular convergence are of psychological origin. These findings do exist as inherent ocular defects in people of stable nervous constitution. Some individuals have never fully ácquired the ability to converge their eyes; they may never have had to use their eyes for close work. A convergence defect may exist associated with a considerable degree of exophoria, or as a result of damage to the oculomotor nuclei. There is, however, in a number of individuals a correlation between the phorias, convergence defects and neurotic constitution. Moreover; a study of our cases indicates that any inherent ocular defect may form the nucleus for an aggregation of hysterical symptoms and signs.

\section{Factors predisposing to the development of ocular symptoms}

From those who develop a hysterical reaction it is almost always possible to derive a history of personal neurotic traits or a family history of psychopathy, or both. And a significantly large number of those who develop ocular signs and symptoms of neurosis give a previous personal history of ocular instability or a family history of eye-trouble. Many of these individuals have suffered previously from " eye-strain," have always been sensitive to glare, and have worn spectacles at school: They have a constitutional liability to develop their symptoms. At the same time, it must always be remembered that in war-time, after a severe traumatic experience, individuals of relatively sound personality may develop hysteria. 
Certain environmental factors are of aetiological importance : conditioning accidents which the individual has suffered, and situations of what may be termed visual stress. Minor head injury is the commonest of conditioning accidents : eight out of 40 cases attributed their symptoms to this cause. One man developed his symptoms after a minor eye injury and another after he had been momentarily blinded by a lightning flash. It is easy to understand that in the production of visual symptoms the visual strains (sun glare, searchlights, darkness, etc.) to which aircrew personnel are subject are predisposing factors. This aspect of flying under active service conditions we have discussed above.

Aircrew personnel are so well looked after from the point of . view of rest, comfort and living conditions generally that, in our opinion, the question of fatigue hardly ever arises. It may, however, be a factor during exceptional periods of stress from continued aerial warfare, or in the case of those engaged in coastal reconnaissance or anti-submarine sweeps entailing long hours of flying over the sea by day and night, frequently at low levels. Individuals who are engaged on routine flying duties over a long period of time, e.g., flying instructors and staff pilots, may find the monotony of their work intolerable. If hysterical symptoms arise it is often all too easy to attribute them to fatigue.

An attempt was made by one of us in examining candidates for aircrew duties to establish a correlation between ocular muscle imbalance and predisposition to psychoneurotic breakdown. Visual standards stricter than those at present officially employed were used in this investigation, and those candidates whose objective convergence was not less than $10 \mathrm{cms}$., or who showed an exophoria of 4 prism dioptres or more as measured by the Maddox Rod at 6 metres distance, were given a short psychiatric interview-if there had been no other ophthalmic abnormality to account for these findings. Only candidates passed as visually fit for some or all aircrew duties were interviewed. In the interviews factors which are considered to predispose to psychoneurotic breakdown were sought in the biographies of the candidates: neurotic traits were scored and expressed in degrees of disposition-nil, slight, considerable, very considerable, severe.

Ten cases of convergence weakness and 4 cases of exophoria were examined. Of the 10 cases of convergence weakness, 4 were found to be very considerably and 1 severely predisposed to breakdown. Other types of muscular imbalance were not examined; and the investigation has not been completed. The numbers already investigated are of course too small to provide significant evidence, but the positive correlation found seems suggestive and worthy of further investigation with controls. As we have stated above, we subscribe to the view that by no means all cases of ocular muscle imbalance occur in neurotic individuals. 


\section{Differential diagnosis}

Reference has already been made to the necessity for finding positive evidence of neurosis in all suspect cases. It should also be borne in mind that organic disease may co-exist with neurosis. The most difficult cases are those of convergènce insufficiency arising after head injury with possible cerebral contusion or damage to the mid-brain and peri-aqueductal region. During cónvalescence from cerebral concussion defective convergence of the eyes may. be noted as an organic finding with or without other evidences of damage to the oculo-motor nuclei. The symptom may exist in association with paralytic squint or abnormality of pupillary reaction, or as an isolated ocular finding. In the latter case it may be associated with defective attention or abnormal fatiguability. When the defective convergence ceases to be an organic finding depends on a variety of factors, particularly (1) the degree of head injury as assessed by the duration of the post-traumatic amnesia or the total picture of neurological damage, (2) the persistence of evidences of ocular or other neurological damage, (3) the personality of the patient and his mental reaction to the total situation. As a hysterical finding it is seen not uncommonly as one of the most persistent signs after moderate head injury in civil compensation cases. It is noteworthy that in some of our cases of defective convergence and of dissociation between ocular. convergence and pupillary contraction no history of head injury was obtained.

A few cases referred for symptoms thought to be of neurotic origin were found on careful examination to be suffering from a small lesion in the region of the macula. This was apparent on detailed examination with the ophthalmoscope and careful examination of the central field by means of a scotometer. (Not infrequently a macular retinopathy has been incorrectly diagnosed in the presence of a doubtful objective abnormality only. Group Captain Keith Lyle considers that the essential criteria for diagnosing this condition are the presence of a small absolute or relative scotoma in the region of the fixation spot and an appearance of abnormal pigmentation or atrophy in the macular region in an old case, or the presence of oedema in a case of recent origin.) In one case an individual who certainly had an affective disorder was found to have an infective retinitis. Retinitis pigmentosa and choroiditis are conditions which must be excluded. In another case of affective disorder over-indulgence in alcohol and tobacco led to the development of tobacco amblyopia. A very puzzling case was that of an individual with convergence spasm, saccadé movements of the eyes, and a complaint of double vision and unsteady gait, in whom the suspicion of a pontine lesion arose. In cases without physical signs, migraine and visual Jacksonian attacks may have to be excluded. 


\section{Treatment}

Treatment măy be considered feasible in cases following a severe traumatic experience and in índividuals who have a considerable number of flying hours or of operational hours to their credit. At first it is nearly always necessary to alter-the environment to suit the person-this may mean temporary grounding, the prescription of daylight flying only, limiting the duration of the flight, or removing the individual from con'ditions of tropical glare. Return to full flying duties may be expected in a small number of relatively stable individuals. Orthoptic treatment of hysterics is unlikely to be permanently successful, although it has been shown that the suggestive and persuasive effect may carry the individual on for some time.

Acknowledgments.-Our thanks are due to Air Marshal Sir Harold Whittinghamm, Director-General Medical Sêrvices, R.A.F., for permission to publish this paper. We thank also the various R.A.F. Ophthalmic Specialists who referred cases to us, and Group Captain Keith Lyle for his helpful criticism of this paper.

\section{REFEREN่CES}

1. Traguair, .H. M. (1942).- "An Introduction to Clinical Perimetry." Fourth Edition. H. Kimpton; London.

2. Hurst, Sir ARThuR (1940).- “"Medical Diseases of War." 'London:

3. Michaelson, I. C. (1943).- " Ocular Manifestations of Neurosis in Soldier\$." Brit. Med. Jl., October 30 , p. 538.

4. Gillespie, Air Commodore R. D. (1944).-Personal Communication.

See also MANN, I. (1940).-Convergence deficiency. Brit. Jl. Ophthal., August, p. 373.

\section{THE TREATMENT OF TRACHOMA* \\ With special reference to local, sulphonamide therapy}

B Y

\section{ARNOLD SORSBY}

LONDON

ONE hundred and thirty-one children were admitted to the trachóma block at White Oak Hospital from 1934 till May 10, 1944, when the block was closed owing to the absence of new admissions. Together with some 40 trachomatous children resident at White Oak Hospital in 1934 and some 20 adults theated as in-patients at the L.C.C. trachoma unit for adults at the Eastern Fever Hospital, a series of some 200 patients treated under ideal conditions for continuous observation was available and has

\footnotetext{
* Received for publication, June 27, 1944.
} 